\title{
Konsep Sinyal Informasi pada Stasiun Pengolahan Limbah Cair PLTBg POME
}

\author{
Stieven N. Rumokoy*1, Dezetty Monika ${ }^{2}$, Langlang Gumilar ${ }^{3}$ \\ ${ }^{1}$ Jurusan Teknik Elektro, Politeknik Negeri Manado, ${ }^{2}$ JurusanTeknik Elektro Politeknik Negeri \\ Jakarta, ${ }^{3}$ Jurusan Teknik Elektro Universitas Negeri Malang \\ Email : ${ }^{* 1}$ rumokoy@ polimdo.ac.id, ${ }^{2}$ dezetty.monika@elektro.pnj.ac.id, \\ langlang.gumilar.ft@um.ac.id
}

\begin{abstract}
Abstrak
Pembangkit Listrik Tenaga Biogas (PLTBg) membutuhkan sistem operasional yang baik. Sistem yang baik dapat dengan jelas diketahui apa yang terjadi di lapangan. Untuk mempermudah mengetahui kondisi lapangan, dapat dengan membuat suatu konsep pembacaan sinyal yang menyatakan kondisi aktual yang sedang terjadi dilapangan. Pada PLTBg yang berasal dari Limbah Cair Kelapa Sawit atau yang sering disebut dengan POME (Palm Oil Mill Effluent), terdapat Stasiun Pengolahan Limbah Cair. Proses pengolahan Limbah Cair harus dioperasikan dengan benar dan aman agar dapat mereduksi kadar limbah dengan hasil samping biogas seperti yang diharapkan. Dalam operasionalnya, dibutuhkan informasi yang benar disetiap peralatan yang terpasang dilapangan. Dengan beragamnya peralatan yang terpasang dilapangan, tentunya dibutuhkan suatu cara untuk memastikan seтиa peralatan dalam kondisi operasi yang benar. Dengan melakukan analisis kebutuhan sinyal sebagai informasi aktual yang sedang terjadi pada stasiun pengolahan limbah cair (dari lapangan kepengontrol utama), maka dapat simpulkan bahwa ada beberapa sinyal status seperti Actifunactif Status Indicator, Level Indicator, Flow Meter Indicator, Temperature Indicator, Pressure Indicator for Liquid dan Pressure Indicator for Gas, perlu untuk diketahui. Sinyalsinyal seperti inilah yang dibutuhkan informasinya dari lapangan (Stasiun Pengolahan Limbah Cair) untuk mempermudah dan atau mengamankan operasional pada PLTBg.
\end{abstract}

Kata Kunci-PLTBg, POME, Sinyal

\begin{abstract}
Biogas Electrical Power Plant require a good operational system. Good operational system could be mean there is a clear information about the condition from field. To make easier to get information from field, a concept of signal reader which picturing actual condition can be build. In Biogas Electrical Power Plant from POME (Palm Oil Mill Effluent), there is a Waste Water Treatment Station. The Operation of Waste Water Treatment Station should be well and safe operated, to reducing hazardous content of the waste water and get Biogas as a side product. On that operation, every equipment in that field need the right information for control purpose. The require signal analysis in waste water treatment station to get information actual condition from field to the main control has been done. It needs some signal such as Actif-unactif Status Indicator, Level Indicator, Flow Meter Indicator, Temperature Indicator, Pressure Indicator for Liquid and Pressure Indicator for Gas, respectively. This kind of signal as an information from field (Waste Water Treatment Station) to make operation easier and safe.
\end{abstract}

Keywords—Biogas Electrical Power Plant, POME, Signal 


\section{PENDAHULUAN}

Industri Kelapa Sawit telah menjadi primadona utama bagi pendapatan Indonesia. Kelapa sawit merupakan salah satu komoditas pertanian utama Indonesia yang telah berkembang [1]. Jumlah luasan Industri kelapa sawit terus meningkat dari tahun-ketahun. Permintaan dunia terhadap hasil industri sawit memicu perkembangan Industri Kelapa Sawit di Indonesia. Perkebunan di sektor swasta memiliki luas area yang lebih besar dibandingkan perkebunan negara dan rakyat [2]. Berdasarkan data FAO, Indonesia merupakan negara produsen kelapa sawit terbesar di ASEAN maupun dunia [3]. Disisi lain, Industri kelapa sawit memiliki potensi besar sebagai penghasil energi. Energi dari limbah Industri kelapa sawit sangat potensial untuk digunakan lebih lanjut. Salah satu contohnya adalah pemanfaatan limbah cair kelapa sawit sebagai penghasil Biogas. Biogas tersebut kemudian dimanfaatkan untuk sebagai bahan bakar Genset Biogas yang kemudian menjadi Listrik.

Pembangkit Listrik Tenaga Biogas (PLTBg) pada umumnya dibagi menjadi tiga bagian besar yaitu, Stasiun Pengolahan Limbah, Stasiun Pengolahan Gas dan Stasiun Pembangkit Listrik, secara berturut-turut. Pada stasiun pengolahan limbah cair dibutuhkan sistem operasional yang baik untuk melancarkan operasional. Limbah cair kelapa sawit (Palm Oil Mill Effluent atau POME) adalah limbah cair yang berminyak dan tidak beracun, berasal dari proses pengolahan minyak kelapa sawit, namun limbah cair tersebut dapat menyebabkan bencana lingkungan apabila tidak dimanfaatkan dan dibuang di kolam terbuka karena akan melepaskan sejumlah besar gas metana dan gas berbahaya lainnya keudara yang menyebabkan terjadinya emisi gas rumah kaca [4]. Teknologi untuk menangkap dan memanfaatkan gas metana yang dihasilkan dari kolam anaerobik pengolahan air limbah telah dikembangkan [5]. Pembangunan PLTBg POME di wilayah perkebunan sawit penting dilakukan untuk menginisiasi PLTBg POME serta sebagai unit percontohan yang akan menjadi sarana pembelajaran bagi industri sejenis [6]. Untuk menghasilkan tenaga listrik yang baik diperlukan pertimbangan yang baik pula mengenai teknologi yang akan digunakan [7]. Pengembangan teknologi untuk menaikan effisiensi baik untuk terus dilakukan [8]. Sistem kontrol dengan proses operasi yang baik sangat mendukung terciptanya pengolahan yang diharapkan [9].

Pada dasarnya komunikasi sinyal adalah komunikasi antara apa yang sedang terjadi di lapangan dengan apa yang diinginkan terjadi dilapangan. Pada tulisan ini, menjelaskan khusus komunikasi sinyal yang dibutuhkan pada stasiun pengolahan limbah cair dari lapangan untuk diolah atau sekedar informasi bagi pengontrol utamaya itu Program Logic Controler dan atau Operator. Untuk signal feedback control tidak dibahas pada tulisan ini.

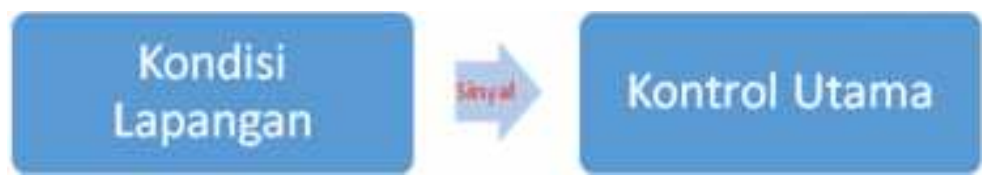

Gambar 1. Sistem yang dibahas

Pada operasi PLTBg, Sistem SCADA (Supervisory Control and Data Acquisition) sangat membantu baik dalam sistem operasi. Pada sistem SCADA di PLTBg hal-hal yang perlu dikontrol berupa sistem operasi pompa, kontrol operasi valve untuk aliran POME, Sludge, Biogas dan lainya. Sistem SCADA telah membantu mempermudah operasional PLTBg. Contoh sistem SCADA pada PLTBg dapat dilihat pada Gambar 2. 


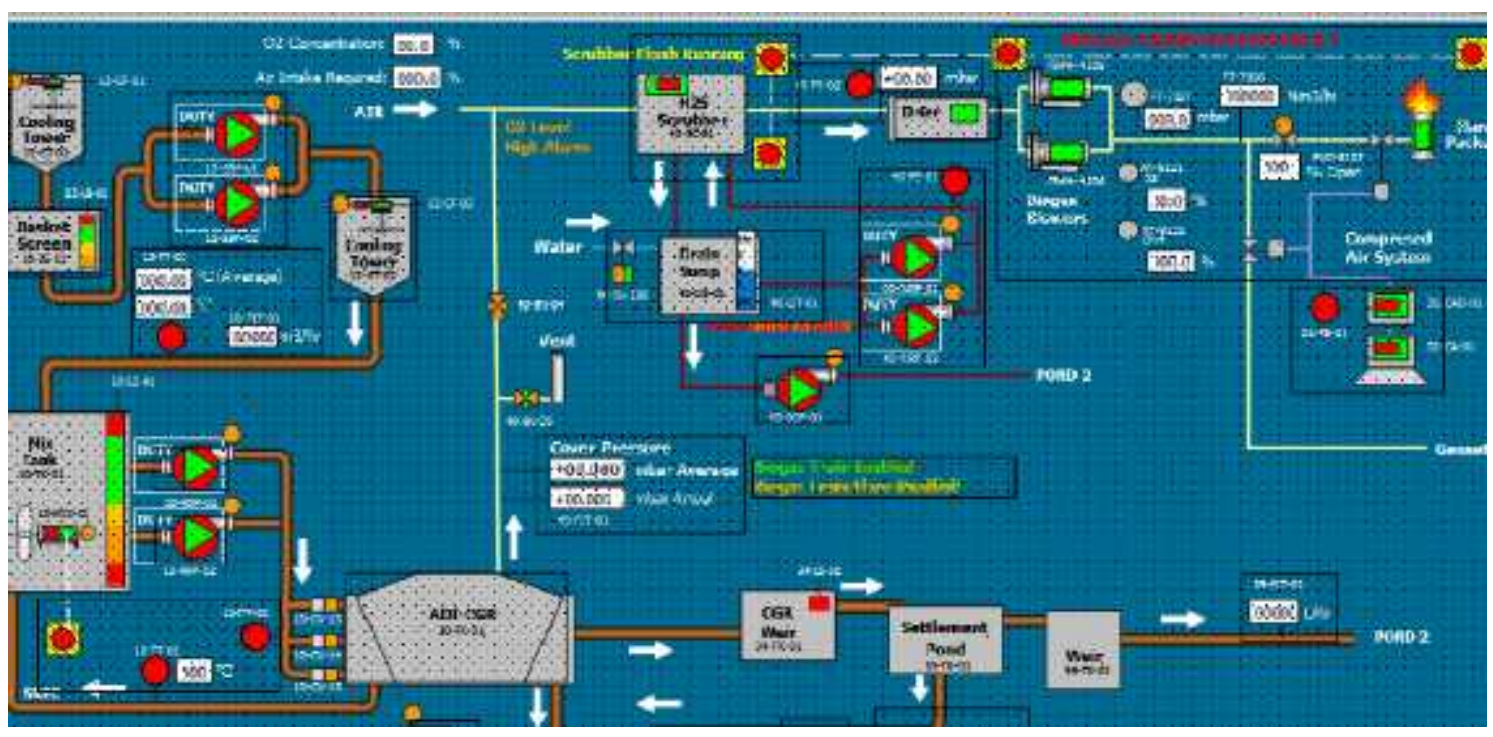

Gambar 2. Tampilan SCADA pada PLTBg

\section{METODE PENELITIAN}

Untuk megetahui kebutuhan sinyal dilapangan, metode analisis kebutuhan telah dilakukan. observasi kebutuhan teknis telah dilakukan dengan cara memperkirakan hal-hal apa saja yang dibutuhkan dilapangan. Metode analisis kebutuhan ini dilakukan dengan mempertimbangkan kondisi real yang akan terjadi. Tahapan yang penelitian dapat dilihat seperti pada gambar dibawah ini.

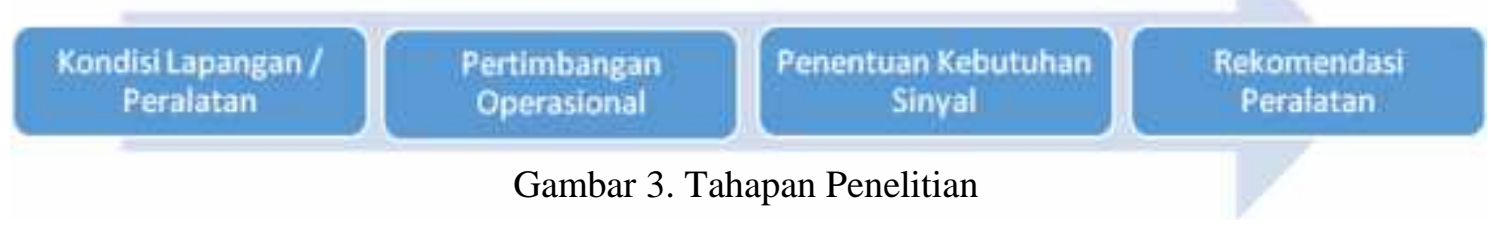

1. Kondisi Lapangan/Peralatan

Analisis awal yang dilaksanakan adalah melihat kondisi lapangan atau kondisi peralatan yang berada pada plant pengolahan limbah cair di Pembangkit Listrik Tenaga Biogas (PLTBg). Melihat ada bagian bagian apa saja dan jenis peralatan apa saja yang perlu mendapatkan perhatian khusus.

2. Pertimbangan Operasional

Analisis selanjutnya adalah pertimbangan untuk melancarkan operasional. Pada tahap ini juga dilakukan analisis untuk melihat faktor keamanan operasional yang dilakukan oleh operator. Mempertimbangkan bagian mana saja yang perlu diberikan sinyal-sinyal khusus untuk memberikan informasi agar kelancaran dan keamanan operasional dapat terpenuhi.

3. Penentuan Kebutuhan Sinyal

Pada tahap ini, dengan mempertimbangkan tahap sebelumnya maka informasi sinyal yang dibutuhkan dari lapangan akan ditentukan. Pertimbangan sinyal dilapangan yang berupa sinyal status I/O atau dalam range tertentu dilakukan pada tahap ini.

4. Rekomendasi Peralatan

Rekomendasi peralatan yang dibutuhkan menyesuaikan kebutuhan sinyal dilapangan. Peralatan ini harus kompatibel dengan Program Logic Controler (PLC) kontrol utama. 
Spesifikasi peralatan harus benar-benar diperhatikan agar peralatan yang ditentukan sesuai dengan kebutuhan.

\section{HASIL DAN PEMBAHASAN}

1. Colling Tower

Colling tower berfungsi untuk mengatur suhu POME agar sesuai dengan suhu yang diharapkan. Pada sistem pengolahan limbah cair, cooling tower berperan penting untuk memastikan kondisi suhu awal yang akan masuk ke sistem sesuai dengan range suhu yang diinginkan. Range suhu POME diatur sesuai dengan tipe bakteri yang dikembangkan. Pada bakteri mesofilik, suhu yang diharapkan yang akan masuk kedalam reaktor adalah sekitar 25$40^{\circ} \mathrm{C}$.

Pada cooling tower seperti pada Gambar 3, POME akan dialirkan melalui pipa di atas cooling tower, kemudian secara perlahan POME akan jatuh tersebar ke dalam cooling tower. Di dalam cooling tower POME akan jatuh mengalir dengan sedikit karena ada kisi-kisi sebelum jatuh kepenampung dasar/bak cooling tower. Saat inilah perpindahan kalor terjadi karena udara lingkungan akan terserap masuk kedalam cooling tower dan dikeluarkan lagi melalui fan yang ada.

Bakdasar pada cooling tower berfungsi sebagai penampung sementara POME, bak ini juga mengontrol maksimum jumlah POME yang secara berkelanjutan akan masuk kedalam sistem. Kebutuhan memasukan POME dalam jumlah tertentu secara berkelanjutan sudah merupakan bagian dari sistem pengolahan limbah Cair.

Berdasarkan kebutuhan dasar operasi cooling tower pada pengolahan limbah cair di Pembangkit Listrik Tenaga Biogas (PLTBg) yang berasal dari POME dibutuhkan kondisi sinyal:

1. Kondisi on Fan

2. Kondisi off Fan

3. Kondisi Emergensi Stop Cooling Tower dioperasikan

4. Kondisi Emergensi Stop Cooling Tower tidak dioperasikan

5. Level Penampung dasar/Bak

6. Jumlah POME yang mengair.

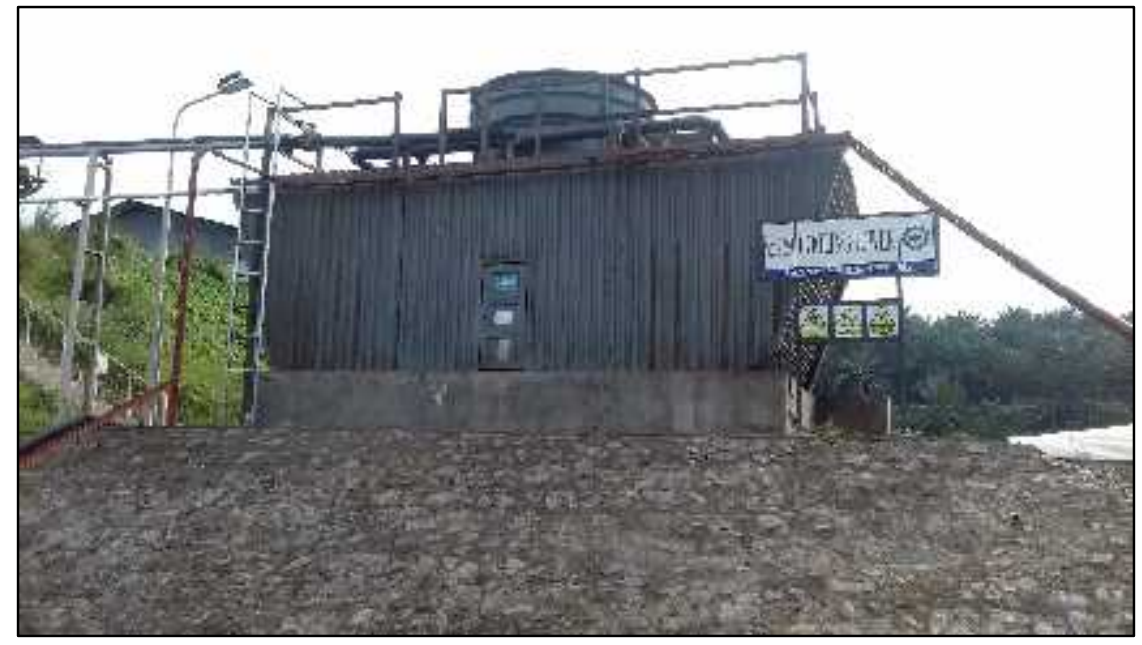

Gambar 4.Cooling Tower

\section{Mix Tank}

Mix tank adalah tempat mencampur POME baru yang berasal dari cooling tower dan POME lama hasil umpan balik dari reaktor. Pencampuran POME bertujuan untuk homogenisasi. Jumlah POME yang dicampur diatur didalam bak penampung dengan mixer untuk mengocok POME baru dan POME lama. Untuk memasukan POME yang telah tercampur yang berasal dari 
Mix Tank, digunakan pompa. Penggunaan pompa ini bertujuan untuk menambah tekanan agar POME dapat masuk dengan lancar kedalam dasar kolam.

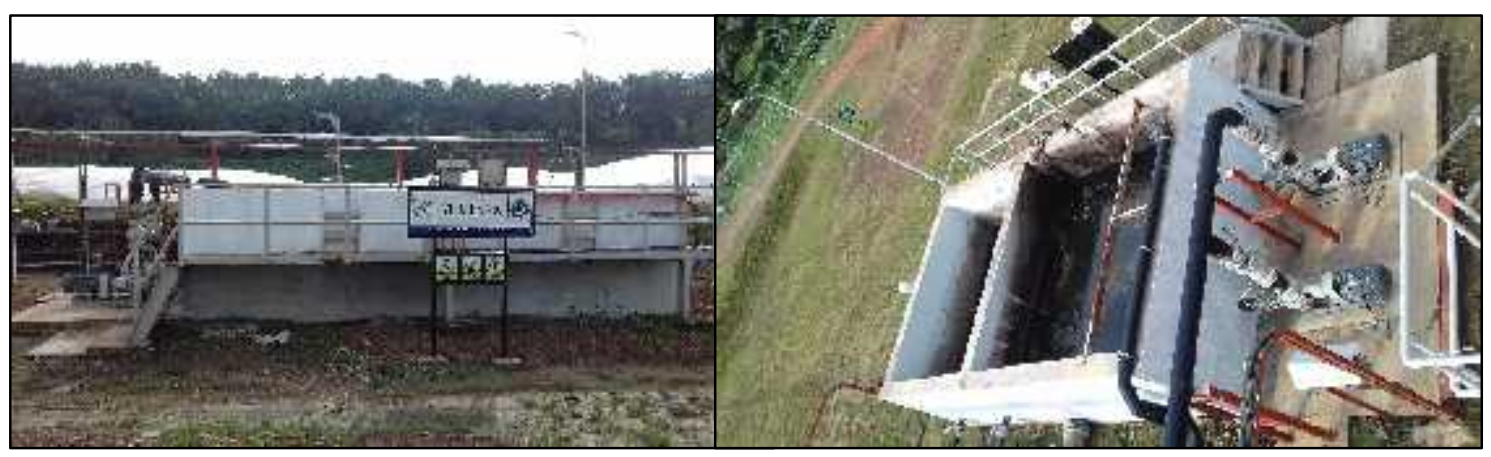

Gambar 5. Mix Tank Tampak Samping dan Atas

Pada Mix Tank terdapat tangki penampung limbah lama, tangki penampung limbah lama ini diambil dari kolam settlement (Settlement Pond). Berdasarkan kebutuhan dasar operasi Mix Tank pada pengolahan limbah cair di pembangkit listrik tenaga biogas yang berasal dari POME dibutuhkan kondisi sinyal:

1. Kondisi on tiap Pompa

2. Kondisi off tiap Pompa

3. Kondisi Emergensi Stop Mix Tank dioperasikan

4. Kondisi Emergensi Stop Mix Tank tidak dioperasikan

5. Level Mix Tank

6. Presure Setelah Pompa

7. Banyaknya POME yang dialirkan

3. Kolam Reaktor

Kolam reaktor adalah tempat proses pembentukan gas metana terjadi sekaligus tempat penguraian kadar limbah POME. Kolam reaktor diatur sedemikian rupa sehingga POME memiliki waktu yang cukup untuk penguraian limbah dan pembentukan gas metana. Pengaliran POME dari Mix Tank diatur berdasarkan jalur masuk POME yang disesuaikan oleh desain. Pengaliran POME diatur bergantian dengan mengatur buka tutup katup/valve sesuai yang diharapkan.

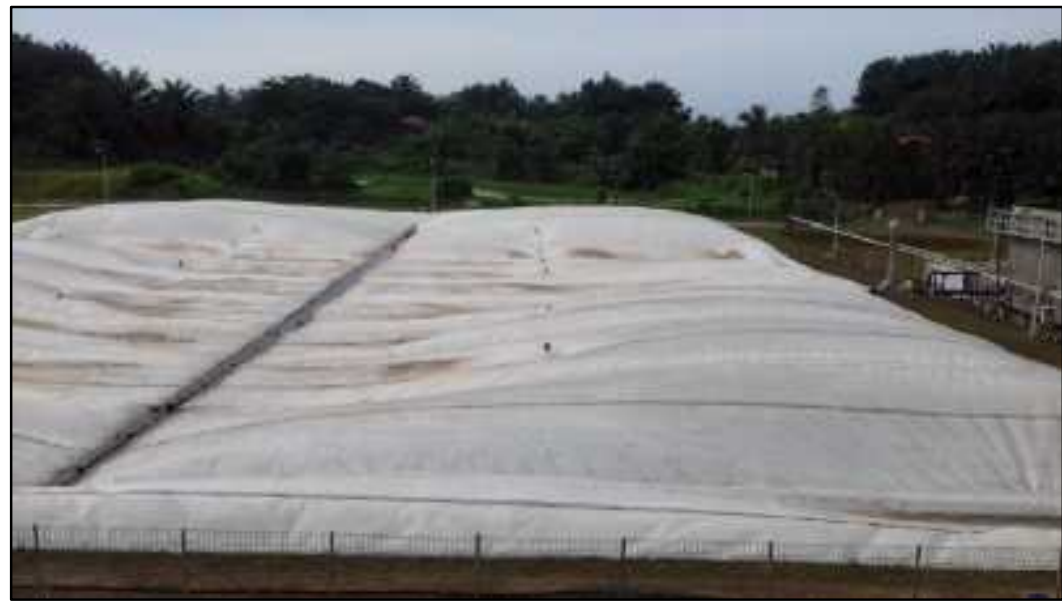

Gambar 6. Kolam Reaktor

Suhu kolam reaktor diharapkan tetap sesuai dengan suhu yang diinginkan, suhu berkisar 25$40^{\circ} \mathrm{C}$ diatur untuk kondisi bakteri mesophilic. Bakteri mesophilic akan aktif hidup dan mengurai 
limbah pada suhu ini. Kondisi kolam reaktor harus dijaga sedemikian rupa agar suhu yang ada dalam kolam reaktor berkisar pada suhu ini.

Jumlah volume kolam reaktor harus tetap terjaga untuk keamanan operasional, pada output kolam reaktor biasanya terdapat sump untuk mengetahui level kolam reaktor. Sump ini digunakan juga sebagai visual kontrol untuk memastikan aliran POME yang keluar menuju tahap selanjutnya. Sump ini juga digunakan sebagai tempat pengambilan sampel pengukuran kadar limbah yang terkandung setelah proses penguraian didalam reaktor.

Pada kolam reaktor, gas metana yang dihasilkanakan terkumpul didalam cover diatas kolam. Sejumlah gas ini akan dikumpulkan sampai untuk digunakan sebagai bahan bakar. Gas bertekanan ini harus dipastikan agar tidak melebihi kapasitas agar reaktor tidak meledak.

Berdasarkan kebutuhan dasar operasi kolam reaktor pada pengolahan limbah cair di pembangkit listrik tenaga biogas yang berasal dari POME dibutuhkan kondisi sinyal:

1. Kondisi on tiap valve input POME

2. Kondisi off tiap valve input $\mathrm{POME}$

3. Level Reaktor

4. Presure Gas

5. Banyaknya POME yang dicampurkan

\section{Settlement Pond}

Settlement Pond adalah kolam penampung sementara setelah proses penguraian pada kolam limbah. Settlement pond juga merupakan tempat penampung untuk umpan balik ke Mix Tank melalui Rans Sump. Untuk memastikan kondisi operasional Settlement Pond berada pada kondisi normal, banyaknya limbah didalam Settlement Pond harus dioperasikan sesuai dengan peruntukannya.

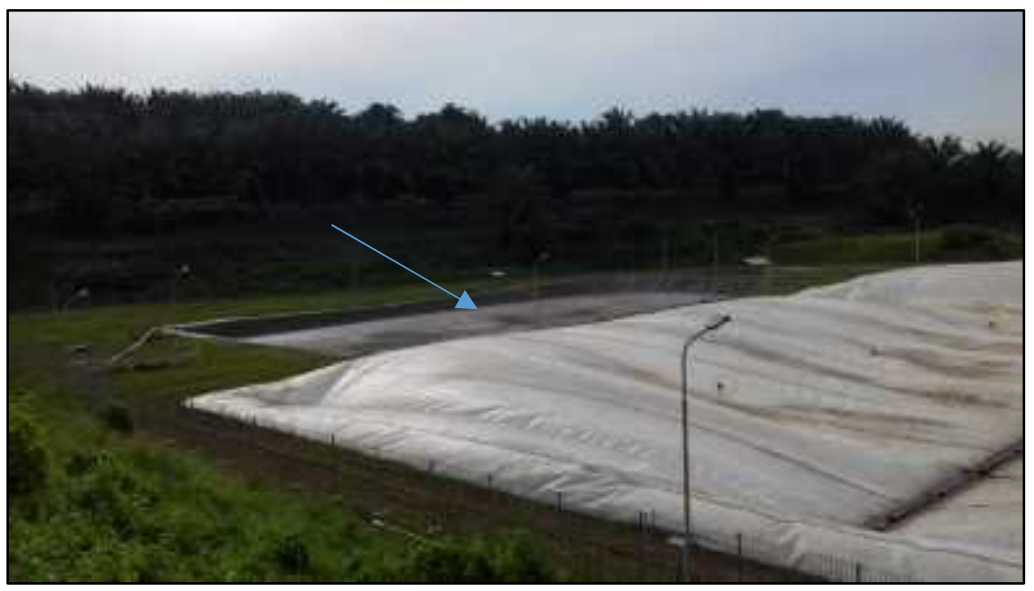

Gambar 7. Settlement Pond

Limbah yang telah terurai kemudian diaplikasikan sesuai pengaturannya, pada umumnya diaplikasikan keperkebunan. Untuk mengetahui Jumlah output limbah yang berasal dari pengolahan limbah cair, dibutuhkan alat ukur pengukur volu melimbah yang keluar dari plant pengolahan limbah cair.

Berdasarkan kebutuhan dasar operasi Settlement Pond pada pengolahan limbah cair di pembangkit listrik tenaga biogas yang berasal dari POME dibutuhkan kondisi sinyal:

1. Level Settlement Pond

2. Presure Gas

3. Banyaknya limbah yang keluar dari plant pengolahan limbah.

5. Analisis Kebutuhan sinyal.

Dari kondisi plant pengolahan limbah cair pada PLTBg diatas maka, kebutuhan sinyal untuk pengaturan dan sebagai pengaman operasi adalah sebagai berikut: 
Tabel 1. kebutuhan sinyal untuk pengaturan dan sebagai pengaman operasi

\begin{tabular}{|c|c|c|c|}
\hline No & Bagian & $\begin{array}{l}\text { Sinyal } \\
\text { dibutuhkan }\end{array}$ & Fungsi sinyal \\
\hline \multirow[t]{7}{*}{1} & \multirow[t]{7}{*}{$\begin{array}{l}\text { Cooling } \\
\text { Tower }\end{array}$} & Fan On & $\begin{array}{l}\text { Sinyal ini berfungsi sebagai penanda apakah fan pada } \\
\text { cooling tower sedang dalam kondisi dioperasikan. }\end{array}$ \\
\hline & & Fan Off & $\begin{array}{l}\text { Sinyal ini berfungsi sebagai penanda apakah fan pada } \\
\text { cooling tower sedang tidak dalam kondisi dioperasikan. }\end{array}$ \\
\hline & & $\begin{array}{l}\text { Emergensi stop } \\
\text { cooling tower on }\end{array}$ & $\begin{array}{l}\text { Sinyal ini berfungsi untuk memberikan status apakah } \\
\text { emergensis top pada area cooling tower sedang diaktifkan. }\end{array}$ \\
\hline & & $\begin{array}{l}\text { Emergensi stop } \\
\text { cooling tower off }\end{array}$ & $\begin{array}{l}\text { Sinyal ini berfungsi untuk memberikan status apakah } \\
\text { emergensi stop pada area cooling tower tidak sedang } \\
\text { diaktifkan. }\end{array}$ \\
\hline & & $\begin{array}{l}\text { Level penampung } \\
\text { dasar/bak }\end{array}$ & $\begin{array}{l}\text { Sinyal ini berfungsi untuk menandakan apakah level pada } \\
\text { penampung beroperasi dalam keadaan normal. }\end{array}$ \\
\hline & & $\begin{array}{l}\text { Jumlah POME yang } \\
\text { mengalir. }\end{array}$ & $\begin{array}{l}\text { Sinyal ini adalah sinyal pemberitahuan jumlah POME yang } \\
\text { mengalir. }\end{array}$ \\
\hline & & Suhu POME & $\begin{array}{l}\text { Sinyal ini dibutuhkan sebagai informasi suhu POME setelah } \\
\text { melewati cooling tower. }\end{array}$ \\
\hline \multirow[t]{7}{*}{2} & \multirow[t]{7}{*}{ Mix Tank } & $\begin{array}{l}\text { Kondisi on tiap } \\
\text { pompa }\end{array}$ & $\begin{array}{l}\text { Sinyal ini berfungsi sebagai penanda apakah pompa pada } \\
\text { mix tank sedang dalam kondisi dioperasikan. }\end{array}$ \\
\hline & & $\begin{array}{l}\text { Kondisi off tiap } \\
\text { pompa }\end{array}$ & $\begin{array}{l}\text { Sinyal ini berfungsi sebagai penanda apakah pompa pada } \\
\text { mix tank tidak sedang dalam kondisi dioperasikan. }\end{array}$ \\
\hline & & $\begin{array}{l}\text { Kondisi emergensi } \\
\text { stop mix tank } \\
\text { dioperasikan }\end{array}$ & $\begin{array}{l}\text { Sinyal ini berfungsi untuk memberikan status apakah } \\
\text { emergensi stop pada area mix tank sedang diaktifkan. }\end{array}$ \\
\hline & & $\begin{array}{l}\text { Kondisi emergensi } \\
\text { stop mix tank tidak } \\
\text { dioperasikan }\end{array}$ & $\begin{array}{l}\text { Sinyal ini berfungsi untuk memberikan status apakah } \\
\text { emergensi stop pada area mix tank tidak sedang diaktifkan. }\end{array}$ \\
\hline & & Level mix tank & $\begin{array}{l}\text { Sinyal ini berfungsi untuk menandakan apakah level pada } \\
\text { mix tank beroperasi dalam keadaan normal. }\end{array}$ \\
\hline & & $\begin{array}{l}\text { Presure setelah } \\
\text { pompa }\end{array}$ & $\begin{array}{l}\text { Sinyal ini adalah sinyal penanda apakah ada aliran sludge } \\
\text { pada pipa, dengan adanya pressure indikator dapat } \\
\text { diketahui apakah sistem berjalan dengan baik, seperti } \\
\text { pompa beroperasi telah dengan baik atau tidak terjadi } \\
\text { penyumbatan pada pipa. }\end{array}$ \\
\hline & & $\begin{array}{l}\text { Banyaknya sludge } \\
\text { yang dicampurkan } \\
\text { kedalam mix tank. }\end{array}$ & $\begin{array}{l}\text { Sinyal ini adalah sinyal pemberitahuan jumlah sludge yang } \\
\text { dialirkan untuk dicampur kedalam mix tank. }\end{array}$ \\
\hline \multirow[t]{5}{*}{3} & \multirow[t]{5}{*}{$\begin{array}{l}\text { Kolam } \\
\text { Reaktor }\end{array}$} & $\begin{array}{l}\text { Kondisi on tiap } \\
\text { valve input } \mathrm{POME}\end{array}$ & $\begin{array}{l}\text { Sinyal ini sebagai penanda apakah posisi valve sedang } \\
\text { dalam kondisi dioperasikan terbuka. }\end{array}$ \\
\hline & & $\begin{array}{l}\text { Kondisi off tiap } \\
\text { valve input POME }\end{array}$ & $\begin{array}{l}\text { Sinyal ini sebagai penanda apakah posisi valve sedang } \\
\text { dalam kondisi dioperasikan tertutup. }\end{array}$ \\
\hline & & Level Reaktor & $\begin{array}{l}\text { Sinyal ini berfungsi untuk menandakan apakah level sludge } \\
\text { pada reaktor sedang beroperasi dalam keadaan normal. }\end{array}$ \\
\hline & & Presure Gas & $\begin{array}{l}\text { Sinyal ini adalah sinyal penanda jumlah biogas didalam } \\
\text { reaktor, Sinyal ini sangat diperlukan karena sebagai } \\
\text { penanda apakah jumlah biogas pada reaktor sudah cukup } \\
\text { untuk digunakan atau tidak, Selain itu sinyal ini sebagai } \\
\text { penanda keamanan dalam operasional agar reaktor tidak } \\
\text { sampai meledak. }\end{array}$ \\
\hline & & Suhu sludge & Sinyal ini adalah sinyal pemberitahuan suhu sludge yang \\
\hline
\end{tabular}




\begin{tabular}{|l|l|l|l|}
\hline 4 & $\begin{array}{l}\text { Settlement } \\
\text { Pond }\end{array}$ & $\begin{array}{l}\text { Level Settlement } \\
\text { Pond }\end{array}$ & $\begin{array}{l}\text { Serada didalam reaktor. } \\
\text { Sada settlementpond sedang beroperasi dalam keadaan } \\
\text { normal. }\end{array}$ \\
\cline { 2 - 4 } & $\begin{array}{l}\text { Banyaknya limbah } \\
\text { yang keluar dari } \\
\text { plant pengolahan } \\
\text { limbah. }\end{array}$ & $\begin{array}{l}\text { Sinyal ini adalah sinyal pemberitahuan jumlah POME yang } \\
\text { mengalir keluar dari plan tpengolahan limbah. }\end{array}$ \\
\hline
\end{tabular}

6. Pengaplikasian alat pendeteksi sinyal yang dibutuhkan.

Berdasarkan kebutuhan sinyal yang diperlukan, maka peralatan yang dapat digunakan untuk mengirim sinyal dari lapangan adalah:

Tabel 2. Peralatan yang dapat digunakan untuk mengirim sinyal

\begin{tabular}{|l|l|l|}
\hline No. & Jenis sinyal & Alat yang dapat digunakan \\
\hline 1 & $\begin{array}{l}\text { Status on/off peralatan seperti } \\
\text { pompa, emergensi stop dan lainnya }\end{array}$ & Actif-unactif Status Indicator \\
\hline 2 & $\begin{array}{l}\text { Status level liquid, dapat digunakan } \\
\text { pada bak atau tangki penampung }\end{array}$ & Level Indicator \\
& &
\end{tabular}




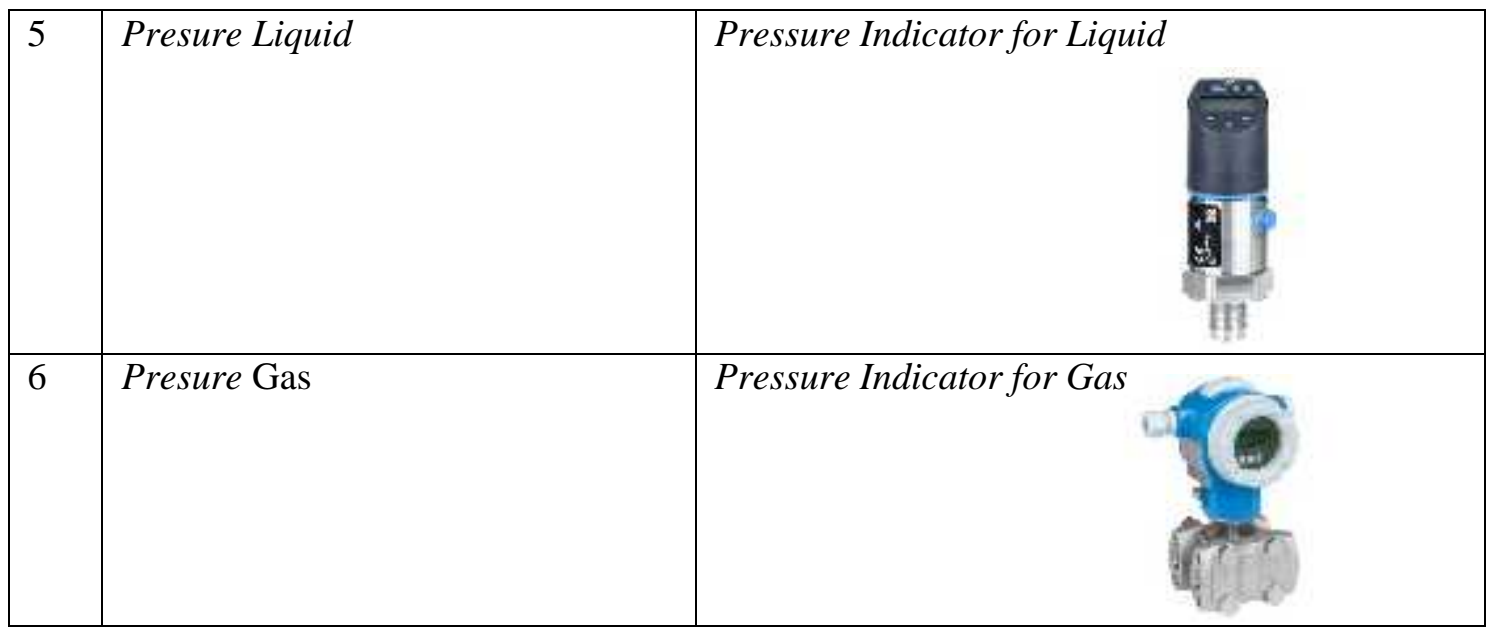

\section{KESIMPULAN}

Berdasarkan hasil diatas, maka dapat disimpulkan bahwa:

1. Sinyal operasional sangat dibutuhkan untuk memastikan pengoperasian pengolahan limbah cair dapat berlangsung dengan baik dan benar.

2. Kondisi operasional lapangan sangat memerlukan sinyal kondisi lapangan untuk memastikan keamanan operasional.

3. Beberapa sinyal seperti Actif-unactif Status Indicator, Level Indicator, Flow Meter Indiator, Temperature Indicator, Pressure Indicator for Liquid dan Pressure Indicator for Gas sangat diperlukan pada Stasiun Pengolahan LimbahCair di PLTBg.

\section{SARAN}

Saran untuk penelitian selanjutnya, metode lebih diperjelas dengan diagram alir penelitian (flow chart). Metode penelitian berisi langkah-langkah penelitian yang dilakukan dan perhitungan-perhitungan untuk mendapatkan hasil. Perlu ditambahkan keterbaruan didalam penelitian dan kontribusi penelitian, sehingga nantinya didapat hasil penelitian yang lebih baik dan dapat diterapkan.

\section{UCAPAN TERIMA KASIH}

Terima kasih kepada Politeknik Negeri Manado, Politeknik Negeri Jakarta, dan Universitas Negeri Malang yang telah memberikan dukungan serta sarana dan prasarana untuk mendukung penelitian ini, sehingga penelitian ini dapat selesai dan menghasilkan sebuah tulisan karya ilmiah untuk diterbitkan pada jurnal nasional. Tidak lupa juga kami sampaikan ucapan terima kasih kepada rekan-rekan kerja disetiap instansi yang telah memberikan ilmunya kepada kami.

\section{DAFTAR PUSTAKA}

[1] A. S. Rahayu and Dkk, Konversi POME Menjadi Biogas. Jakarta Selatan: Winrock International, 2015.

[2] D. D. Hendaryati, "Statistik Perkebunan Indonesia 2015 -2017 Kelapa Sawit," 2017.

[3] L. Nuryati, Outlook Kelapa Sawit Komoditas Pertanian Subsektor Perkebunan. Pusat Data dan Sistem Informasi Pertanian Sek Jen - Kementerian Pertanian, 2016.

[4] Y. M. Alkusma, H. Hermawan, and H. Hadiyanto, "Pengembangan Potensi Energi Alternatif Dengan Pemanfaatan Limbah Cair Kelapa Sawit Sebagai Sumber Energi Baru 
Terbarukan Di Kabupaten Kotawaringin Timur,” J. Ilmu Lingkung., vol. 14, no. 2, p. 96, 2016.

[5] I. Febijanto, "Potensi Penangkapan Gas Metana Dan Pemanfaatannya Sebagai Bahan Bakar Pembangkit Listrik Di Ptpn Vi Jambi," JUnrnal Ilmu Teknol. Energi, vol. 1, no. 10, pp. 30-47, 2010.

[6] A. Zulkifli, "ANALISIS KELAYAKAN POTENSI PEMBANGUNAN PLTBg POME DI WILAYAH PERKEBUNAN SAWIT,” J. Pasti, vol. X, no. 2, pp. 192-207, 2016.

[7] N. Aghamohammadi, S. S. Reginald, A. Shamiri, A. A. Zinatizadeh, L. P. Wong, and N. M. B. N. Sulaiman, "An investigation of sustainable power generation from oil palm biomass: A case study in Sarawak," Sustain., vol. 8, no. 5, pp. 1-19, 2016.

[8] P. Scherer, "Operating Analytics of Biogas Plants to Improve Efficiency and to Ensure Process Stability Operating Analytics of Biogas Plants to Improve Efficiency and to Ensure Process Stability," no. September 2007, 2017.

[9] M. Gospodinov, E. Gospodinova, and K. Cheshmedjiev, "SCADA System for Management and Visualization in Generation of Renewable Energy from Biomass," no. October, 2014. 